\title{
The impact of liquidity on inflation-linked bonds: A hypothetical indexed bonds approach
}

Julia Auckenthaler, Alexander Kupfer, Rupert Sendlhofer

Working Papers in Economics and Statistics

2014-05

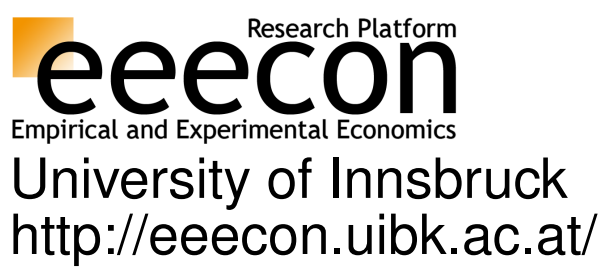




\section{University of Innsbruck \\ Working Papers in Economics and Statistics}

The series is jointly edited and published by

- Department of Economics

- Department of Public Finance

- Department of Statistics

Contact Address:

University of Innsbruck

Department of Public Finance

Universitaetsstrasse 15

A-6020 Innsbruck

Austria

Tel: $\quad$ + 435125077171

Fax: $\quad+435125072970$

E-mail: eeecon@uibk.ac.at

The most recent version of all working papers can be downloaded at http://eeecon.uibk.ac.at/wopec/

For a list of recent papers see the backpages of this paper. 


\title{
The impact of liquidity on inflation-linked bonds: A hypothetical indexed bonds approach*
}

\author{
Julia Auckenthaler $†$ Alexander Kupfer; and Rupert Sendlhofer ${ }^{\S}$ \\ Working Paper
}

March 3, 2014

\begin{abstract}
The sovereign's intention to issue inflation-linked bonds (ILB) is to save money. More than 15 years' experience with this financial instrument in the United States and in several other countries has led to the conclusion that these bonds are costly and basically characterized by low liquidity issues. Recently, various papers have started to analyze the impact of liquidity on ILB yields. This paper summarizes studies concerning ILB liquidity at a glance and adds a new estimation strategy of the liquidity premium based on Campbell \& Shiller's (1996) hypothetical ILB yields. We calculate the difference between observed and hypothetical ILB yields, regress this time series on a set of ILB-specific liquidity as well as general market uncertainty measures and find statistically and economically significant effects of the liquidity measures for the United States, the United Kingdom and Canada.
\end{abstract}

JEL classification: G12, G01, H63

Keywords: Inflation-linked bonds, liquidity, hypothetical yields.

\footnotetext{
${ }^{*}$ We thank Herbert Stocker, Janette Walde, Katrin Wibmer and Achim Zeileis for helpful discussions and comments. And, in particular, we thank Matthias Bank for carefully reading the manuscript and many constructive suggestions. All remaining errors are our own. Kupfer A. gratefully acknowledges financial support from the University of Innsbruck and the Tiroler Wissenschaftsfonds.

${ }^{\dagger}$ Doctoral student, University of Innsbruck

${ }^{\ddagger}$ Department of Banking and Finance, University of Innsbruck, Universitätsstrasse 15, 6020 Innsbruck, Austria, +43(0)512 5077581, email: alexander.kupfer@uibk.ac.at (corresponding author)

$\S$ Department of Public Finance, University of Innsbruck, Universitätsstrasse 15, 6020 Innsbruck, Austria, +43(0)512 5077158, email: rupert.sendlhofer@uibk.ac.at
} 


\section{Introduction}

Inflation-linked bonds (ILB) are a financial instrument which is potentially beneficial for issuers, investors and policy makers. Their feature of inflation compensation has advantages for investors since these bonds have an inflation protection as well as for issuers through saving the inflation risk premium. In addition, policy makers gain market-implied inflation expectations from the yields of ILB. See Deacon et al. (2004) or Shen (1998) for a comprehensive overview of ILB advantages.

It is important to discuss in more detail potential savings for Treasuries by issuing such bonds. Several studies in the late 1990s and early 2000s investigate the size of the inflation risk premium in order to determine the potential savings for Treasuries by issuing such bonds. ${ }^{1}$ However, the current ILB history in the United States was shaped by too high yields in comparison to nominal bond yields. In this context, recent studies investigate these high ILB yields focusing on liquidity-based explanations. In a first step, all these studies extract a time series which includes the potential liquidity premium. The second step, a regression of the relevant time series on several liquidity measures, is more or less similar for all studies, the first step (i.e., the extraction of the relevant time series), however, differs considerably over the existing studies.

The paper of D'Amico et al. (2010) includes the liquidity premium in a term structure model. The authors create a 3-factor affine term structure model for yields of ILB issued by the US Treasury. ${ }^{2}$ They find that an important factor in the observed yields cannot be captured by the 3-factor model since it exhibits considerable pricing errors and delivers inaccurate implications for the break-even inflation rate. Consequently, the authors include a fourth factor in the model and get results for the expected inflation which are comparable with the values of the Survey of Professional Forecasters. The authors show that this fourth factor can be attributed to a substantial liquidity premium since it is highly correlated with a range of liquidity measures. In a regression analysis, D'Amico et al. (2010) are able to explain about $80 \%$ of the variation of the liquidity premium.

\footnotetext{
${ }^{1}$ The basic idea of issuing ILB was to save the inflation risk premium which is present in the case of nominal bonds but does not exist in ILB. See, e.g., Campbell \& Shiller (1996).

${ }^{2}$ Usually, these securities are called Treasury inflation protected securities (TIPS). However, for simplicity, we generally use the term ILB for inflation-linked securities in the remaining part of the paper.
} 
Pflueger \& Viceira (2011) as well as Gürkaynak et al. (2010) use break-even inflation rates as relevant times series to determine the liquidity premium in ILB yields. Pflueger \& Viceira (2011) regress the break-even inflation rate on a set of four liquidity measures of which two are ILB-specific (i.e., ILB transaction volume and the financing cost for buying ILB). The estimation shows significant results with signs consistent with theory. The underlying idea of this approach is that a liquidity premium will be inversely included in the break-even inflation rate since this rate is defined as the difference between the yields of nominal bonds and ILB. The break-even inflation rate declines with lower liquidity (i.e., a higher liquidity premium) in the ILB market. Hence, a low break-even inflation rate is caused by high, illiquid ILB yields. Similar to Pflueger \& Viceira (2011), Gürkaynak et al. (2010) regress five and ten year break-even inflation rates on two liquidity proxies which are trading activity and overall market liquidity. They find a high liquidity premium during the first years of the issuance and a rather moderate premium between 1999 and 2005. Furthermore, with the beginning of the financial crisis the premium considerably increased again.

A partly different procedure is adopted by Grishchenko \& Huang (2013) and Shen (2006). Grishchenko \& Huang (2013) estimate the magnitude of the inflation-risk premium and control for liquidity problems in their estimation. They regress the inflation-risk premium on a set of liquidity measures to get a liquidity-corrected premium. They calculate an average liquidity adjustment of 13 basis points. Similarly, Shen (2006) calculates the difference between a survey forecast measure of inflation and the break-even inflation rate of which only the second is potentially biased by liquidity issues. Analogous to Grishchenko \& Huang (2013), this series is again regressed on a set of liquidity measures and a liquidity premium declining over time is detected.

We align ourselves with this stream of literature and apply the concept of hypothetical ILB yields of Campbell \& Shiller (1996) and Campbell et al. (2009) to estimate the liquidity premium. More precisely, we calculate hypothetical ILB yields for the United States, the United Kingdom and Canada and compare these synthesized yields with their observed counterparts. We regress the difference between these two times series, called GAP in the remainder of the paper, on some measures for liquidity in order to determine the impact of liquidity.

The approach to use hypothetical ILB yields for the determination of the 
liquidity premium is different from existing methods and has some important advantages: We expect that the usage of financial market data instead of survey data improves the accuracy of our model. Furthermore, using 3-month T-bill rates ensures to a large extent that neither a liquidity premium nor an inflation risk premium biases the input variables. And finally, the vector autoregression (VAR) model is a rather simple approach in comparison to, for instance, the 4-factor model of D'Amico et al. (2010).

The difference between observed and hypothetical ILB yields (= the GAP series) is the basis for the regression analysis in which we show to what extent this difference is related to the liquidity of ILB. We use two ILB-specific as well as some general liquidity measures in our estimation and employ a dummy variable for the financial crisis which is endogenously determined by the Quandt-Andrews breakpoint test. For all three countries, we find statistically and economically significant effects of the liquidity measures.

The remainder of this paper is structured as follows: Section 2 reviews the concept of hypothetical ILB yields. Section 3 includes the regression analysis to determine the influence of liquidity and finally, section 4 concludes.

\section{Hypothetical inflation-linked bonds}

The basis for the regression analysis in section 3 is the difference between observed and hypothetical ILB yields (= the GAP series). Observed ILB yields are available from financial markets and hypothetical ILB yields are calculated on the basis of Campbell \& Shiller's (1996) study. Campbell \& Shiller (1996) calculate hypothetical ILB yields in order to analyze the properties of indexed-linked securities. Analyzing observed ILB yields was impossible at this time since there had not been issued any ILB in the United States so far.

They use 3-month nominal T-bill rates and inflation rates within a VAR system to forecast quarterly real interest rates. On the basis of these forecasts the authors calculate hypothetical long-term yields of ILB. They assume that the expected real returns on indexed bonds of all maturities equal the averaged expected real returns of short-term nominal T-bill rates plus a constant. This procedure will fit the movements of the ILB yield curve if the risk premia are constant, but it will not correctly estimate the level of the yield curve. Nowadays, 
since ILB yields are available, it is possible to compare hypothetical with observed yields of ILB and they show a high correlation for the United States as well as for the United Kingdom (see Campbell et al. (2009)).

In more detail, the Fisher equation ${ }^{3}$ which explains the relationship of inflation rate, nominal and real interest rates is used to calculate hypothetical ILB yields. The ex post real 3-month T-bill rate is calculated by subtracting the inflation rate from the nominal 3-month T-bill rate. Within a VAR model ex ante real 3-month T-bill rates are estimated which are the 1-quarter forecasts from the VAR system. ${ }^{4}$ A great advantage of the VAR model is that we do not have to differentiate between endogenous and exogenous variables since they are all endogenous. Thus, the VAR specification includes the nominal T-bill yields, the real T-bill yields and the inflation rate, respectively:

$$
\begin{aligned}
y_{t}^{\text {real }} & =\alpha_{0}+\alpha_{1} y_{t-1}^{\text {real }}+\alpha_{2} y_{t-2}^{\text {nom }}+\alpha_{3} \pi_{t-2}^{Y}+u_{t}^{\text {real }} \\
y_{t-1}^{\text {nom }} & =\beta_{0}+\beta_{1} y_{t-1}^{\text {real }}+\beta_{2} y_{t-2}^{\text {nom }}+\beta_{3} \pi_{t-2}^{Y}+u_{t}^{\text {nom }} \\
\pi_{t-1}^{Y} & =\gamma_{0}+\gamma_{1} y_{t-1}^{\text {real }}+\gamma_{2} y_{t-2}^{\text {nom }}+\gamma_{3} \pi_{t-2}^{Y}+u_{t}^{\pi}
\end{aligned}
$$

where $y_{t}^{\text {real }}$ is the real T-bill yield, $y_{t-1}^{n o m}$ is the lagged nominal T-bill yield, $\pi_{t-1}^{Y}$ is the inflation rate of the previous year and $u_{t}$ is the stochastic error term of the respective equation. ${ }^{5}$ We solely use this VAR system to calculate the fitted values of the real interest rate and subsequently perform a dynamic forecast of these fitted values. To obtain the hypothetical yields on a $k$-quarter ILB, the ex ante real T-bill yields are forecasted over the next $k$ quarters. The mean of these $k$ forecasts represents then the hypothetical yield on a $k$-quarter ILB, e.g., the average of a forecast of 40 quarters is the hypothetical yield on a 10 year ILB.

Note that in hypothetical ILB yields basically no risk premia will be present due to the use of 3-month T-bill rates. Therefore risk premia that exist in ob-

\footnotetext{
${ }^{3}$ The nominal interest rate is the sum of the real interest rate and the average expected rate of inflation plus their cross product: $i=r+\pi^{e}+\left(r \times \pi^{e}\right)$, where $i$ and $r$ are the nominal and real interest rate, respectively, and $\pi^{e}$ denotes the expected inflation rate. The equation is derived from $1+i=(1+r)\left(1+\pi^{e}\right)$. However, for small values the cross product is negligible and we get $i=r+\pi^{e}$ (see, e.g., Mishkin (2003)).

${ }^{4}$ When we refer to real interest rates, we mean the ex post real yields on 3-month nominal T-bills. In contrast, we call the forecasts of the real yields on 3-month nominal T-bills always ex ante real yields.

${ }^{5} \mathrm{~A}$ detailed explanation of the construction of hypothetical ILB yields can be found in the Appendix of this paper.
} 
served yields will be revealed by subtracting hypothetical from observed ILB yields. Figure 1 illustrates the most important (risk) premia for nominal as well as for inflation-linked bond yields. In addition, Figure 1 also sheds light on the impact of risk premia on break-even inflation rates. The upper panel of Figure 1 shows the case in which no risk premia are present and the yield of a nominal bond (left side) solely consists of the real yield and the expected inflation. On the contrary, the yield of an ILB (right side) only contains the real yield. In this unbiased case, the expected inflation equals the break-even inflation rate and therefore, the break-even inflation rate is a good measure to reveal inflation expectations (instead of using surveys for instance).

The lower panel of Figure 1 illustrates the case of biased yields for both types of bonds. Nominal bond yields can comprise both inflation risk and liquidity premia. However, the liquidity premium is expected to be very low since the amount of nominal debt in developed countries is typically high and represents a very liquid market. The inflation risk premium emerges due to uncertain inflation expectations. The higher the variance of inflation expectations, the higher will be this risk premium. Campbell \& Shiller (1996), among others, determine its magnitude and estimate the inflation risk premium for 5-year nominal US Treasury securities between 50 and 100 basis points. Biased yields of ILB, however, only include the liquidity premium since investors are compensated for inflation and do therefore not demand a risk premium for it. Since ILB are only issued in small amounts and less actively traded than nominal bonds liquidity is a substantial problem. The resulting high liquidity premium leads to high ILB yields which bias indirectly the break-even inflation rate (i.e., the break-even inflation rate decreases and is therefore not suitable as an appropriate measure for inflation expectations). In addition, a high liquidity premium in ILB yields also reduces potential savings for the Treasury by issuing this type of bonds. For all these reasons, it is fairly important to analyze whether liquidity is an issue in ILB yields and - if this is the case - to capture the effects of liquidity.

In Figure 2 we show the resulting GAP series (i.e., the difference between observed and hypothetical ILB yields) for the United States, United Kingdom and Canada. If ILB would be very liquid, their yields should not contain a liquidity premium and the GAP series should be a constant due to the calculation of hypothetical ILB yields. However, as we can see in Figure 2, the GAP series 


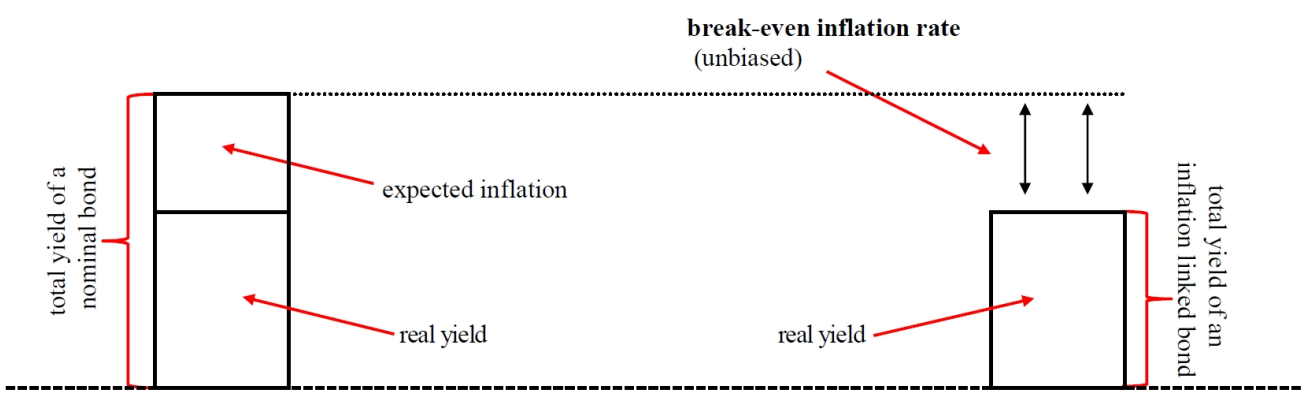

(a) unbiased yields

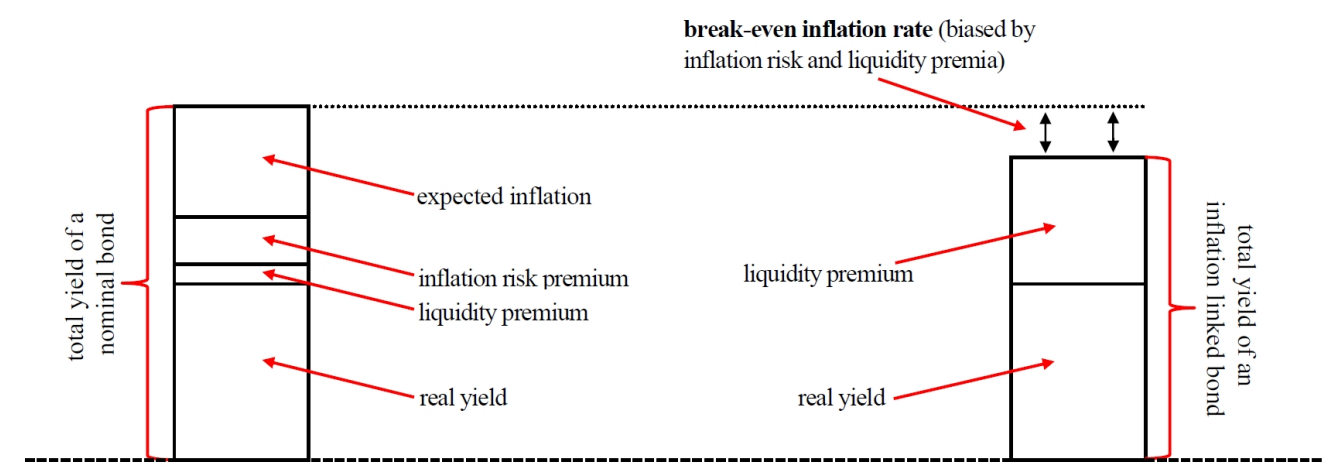

(b) yields biased by inflation risk and liquidity premia

Figure 1: Components of nominal bond yields (left) and inflation-linked bond yields (right).

for all three countries are not constant at all meaning that the series could be biased by one or more risk premia. In the next section we test whether these movements can be explained by some ILB-specific liquidity measures. The graph already indicates that during the financial crisis differences between observed and hypothetical ILB yields are rather high. This is in line with existing literature arguing that illiquid securities obtain a considerable liquidity premium during periods of financial turmoil (see, e.g., Beber et al. (2009)).

\section{$3 \quad$ Regression analysis}

In this section we investigate if and to what extent the difference between observed and hypothetical ILB yields is related to the liquidity of ILB. In order to analyze 


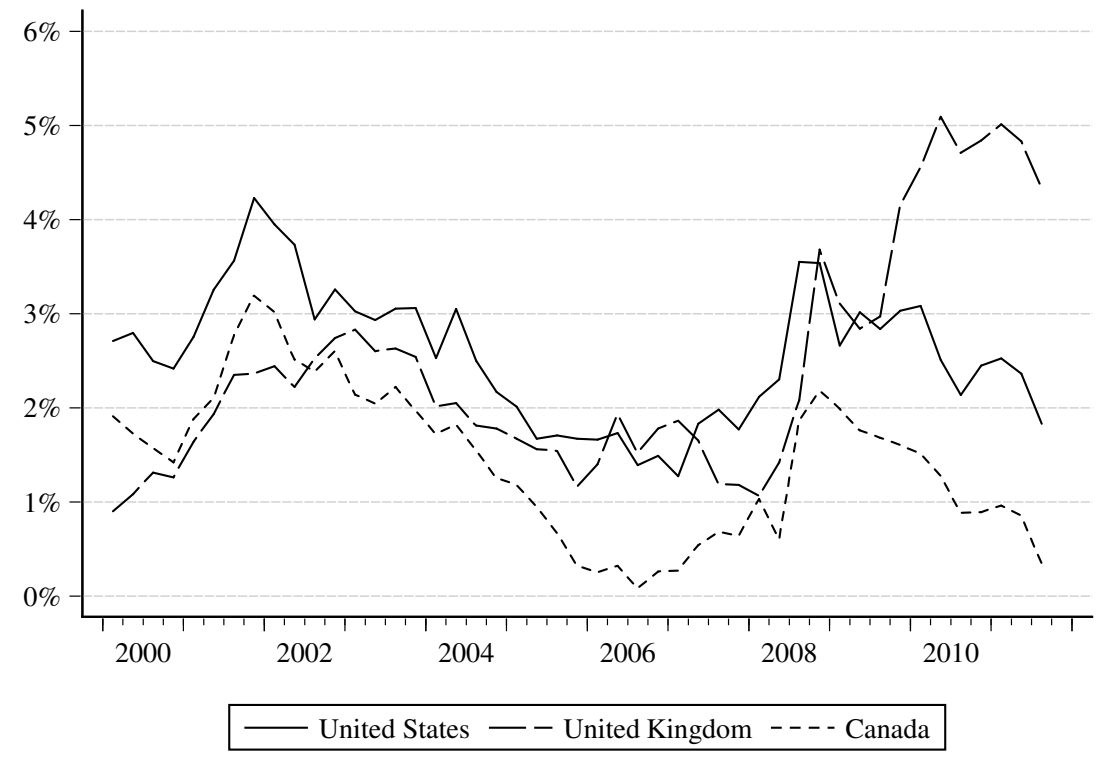

Figure 2: GAP series for the United States, United Kingdom and Canada.

Notes: The GAP series is the difference between observed ILB yields and hypothetical ILB yields. Observed ILB yields are extracted from the Bloomberg database and the construction of hypothetical ILB yields is described in detail in the Appendix of this paper.

this relationship we will make use of ordinary least squares (OLS) and two-stage least squares (TSLS) estimations. At first, we shortly describe the data used. We concentrate on the regressors of the analysis since the regressand (= the GAP series) has already been explained in the section before (see also Figure 2).

\subsection{Data}

As ILB-specific liquidity measures we use the share of ILB (i) in primary dealer transactions (ILB share in transactions) and (ii) in outstanding marketable debt (ILB share in debt). The measures refer to either all primary dealer government debt transactions (in case of (i)) or the country's total debt (in case of (ii)). Higher shares of ILB in transactions and/or outstanding debt should lead to a higher ILB liquidity. A higher liquidity should lower the liquidity premium and result in a lower GAP. We cannot be absolutely sure that the liquidity measures 
are exogenous and independent from the GAP. In our point of view the GAP series is the result of a simulation exercise and should not be seen as a kind of price variable. But one can argue that the GAP is at least a part of the observed ILB yields which do influence the amount of ILB on the market. As a remedy for this possible endogeneity we apply TSLS estimations in the sense of a robustness test for the simple OLS regression results. As instruments for the ILB shares we use the one period lagged values of the liquidity measures. These ILB shares of the last quarter should not be influenced by the actual GAP.

ILB shares of primary dealer transactions are collected from the Federal Reserve Bank of New York for the United States, from the Debt Management Office for the United Kingdom and from the Bank of Canada for Canada. Data is available starting in 2001 for the United States and the United Kingdom and in 2003 for Canada in a weekly frequency. Since hypothetical ILB yields are calculated on a quarterly basis, we sum up weekly transaction volumes for the relevant quarter. Concerning ILB shares in outstanding debt relevant data sources are Treasury Direct for the United States and again the Debt Mangement Office and the Bank of Canada for the United Kingdom and Canada, respectively. We average the monthly data over the entire quarter to use it for the regression analysis.

Note that these two ILB-specific liquidity measures represent different aspects of ILB importance. The first indicator (ILB share in transactions) is a turnover measure and shows the trading impact of ILB relative to all government debt. The second indicator (ILB share in debt) describes the stock of ILB relative to total debt. It is obvious that these two indicators measure different issues: Suppose, for instance, that a great portion of ILB is held in buy-and-hold portfolios which can be seen in the second measure but not in the first one.

In addition to these two ILB-specific regressors we also include some general measures for financial markets' uncertainty since they could influence the difference between observed and hypothetical ILB yields (see also D'Amico et al. (2010)). A higher uncertainty should have a more pronounced effect on observed long-run yields because hypothetical yields are synthesized from short-run variables which do not appropriately display long-run risks. As a consequence a higher uncertainty could lead to an increasing GAP. We use the following set of uncertainty measures: First, we look at the implied volatilities of important national financial indicators. For the United States we use the implied volatility 
of 10-year future notes and of S\&P500. For the other two countries just one of these indicators is available (implied volatility of FTSE for the United Kingdom and of 10-year future notes for Canada). Second, we consider the spread between interbank interest rates and the country specific federal funds rate.

The beginning of each country's estimation period depends mainly on the availability of the ILB-specific liquidity measures. The estimation period for the United States starts in 2001Q3 and ends in 2011Q3. For the United Kingdom and Canada the periods are 2001Q1 to 2011Q3 and 2003Q4 to 2011Q3, respectively.

\subsection{Results}

For each country we start with a baseline estimation. In all three cases we are confronted with autocorrelation which generally is a sign for misspecification. In our case we interpret this as a sign for structural breaks. This interpretation is self-evident as much of our data is affected by the financial crisis. In further estimations we therefore include a dummy variable which is endogenously determined by the Quandt-Andrews breakpoint test. If autocorrelation is still present, we use a second dummy to control for outliers. Finally, we perform TSLS estimations as a robustness test for the simple OLS regression results.

\section{United States}

Starting with a simple OLS baseline regression (see column (I) in Table 1), one observes that this regression suffers from autocorrelation based on the BreuschGodfrey serial correlation Lagrange Multiplier (LM) test. ${ }^{6}$ We endogenously determine the structural break date with the Quandt-Andrews breakpoint test. The test rejects the null hypothesis of no breakpoints (p-value $<0.1 \%$ ) and the most likely breakpoint location is in the third quarter of 2008. This breakpoint is closely related to the financial crisis. In a next step we estimate our regression with a dummy variable (D1) which controls for the financial crisis effects on GAP. With this dummy we get rid of the autocorrelation. The null hypothesis of no first-order serial correlation cannot be rejected (see column (II) in Table 1). Our

\footnotetext{
${ }^{6}$ We report the p-value of the LM test statistic for the null hypothesis of no first-order serial correlation with all the estimation results. If we cannot reject the null hypothesis of no firstorder serial correlation we test for higher order serial correlation (up to an order of five) and take a look at the correlogram of residuals. For all relevant estimations we could not find any higher form of serial correlation.
} 
estimation shows that higher liquidity goes hand in hand with a lower GAP. The results are significant on the $1 \%$ level. As expected, a higher spread between interbank interest rates and the federal funds rate leads to a higher GAP (also significant on the $1 \%$ level). Whereas the effects of other volatility measures (implied volatility of US 10-year notes and of S\&P500) are insignificant. As a robustness check we use instruments for the liquidity measures. For the TSLS estimation (see column (III) in Table 1) we use the one period lagged values of the ILB share in transactions and of the ILB share in debt as instruments. ${ }^{7}$ The estimation results do not change very much and are therefore rather robust. We test whether the orthogonality condition holds for our instruments, i.e. whether our instruments are exogenous. On the basis of the $\mathrm{C}$ test we cannot reject the null hypothesis of our instruments being exogenous (p-value: 0.89). ${ }^{8}$ With the help of the TSLS estimation results we can test for endogeneity of the liqudity measures. On the basis of the Durbin-Wu-Hausman test we cannot reject the null hypothesis of exogeneity of these regressors ( $\mathrm{p}$-value: 0.19). In this case OLS is an appropriate estimation strategy and using TSLS would only result in lower efficiency (see the increasing standard errors in the TSLS estimation results). For the ILB share in debt this would even lead to insignificant results.

[Table 1 about here.]

Let us explain the coefficients of the liquidity measures in the OLS estimation (see column (II) in Table 1): A higher share of ILB in transactions (e.g., an increase of $1 \%$-point) would result ceteris paribus in a decrease of the GAP (e.g., a decrease of $1.05 \%$-points). Such an increase in the share takes place between 2001 and 2011, the share increases from approx. $0.7 \%$ to $1.7 \%$. If we apply the marginal effect we get a decrease in the GAP (ceteris paribus) of 1.05\%-points. In addition, a higher share of ILB in debt (e.g., an increase of 1\%-point) would result ceteris paribus in a decrease of the GAP (e.g., a decrease of $0.17 \%$-points). The share of ILB in debt increases from approx. $4.6 \%$ to $7.3 \%$ in the estimation

${ }^{7}$ These instruments are highly correlated with the explanatory variables in question. For all three countries we regress each liquidity measure on the two instruments and a constant. In all cases the F-test rejects the null hypothesis of both coefficients being zero at a significance level lower than $0,1 \%$.

${ }^{8} \mathrm{In}$ order to compute the $\mathrm{C}$ test we have to include further instruments. We make use of the two period lagged values of the ILB share in transactions and of the ILB share in debt for all three countries. 
period which leads ceteris paribus to a decrease in the GAP of $0.46 \%$-points. In the same time period the actual GAP decreases from $3.56 \%$ to $1.83 \%$. Without doubt this decrease is the result of various effects, but at least the marginal effects of the liquidity measures can explain a large part of the lower GAP.

Finally, we analyze whether the influence of the liquidity measures on the GAP series is different during the financial crisis (see column (IV) in Table 1). We therefore include interaction terms with the significant regressors of the OLS estimation (see column (II) in Table 1): The endogenously determined dummy variable interacts with ILB share in transactions, ILB share in debt and the interest rate spread, respectively. All interaction terms, however, have insignificant coefficients implying that we cannot make a statement concerning the particular impact of the liquidity measures during the financial crisis.

\section{United Kingdom}

For the United Kingdom we start with the same simple OLS regression (see column (I) in Table 2). As expected, this regression also suffers from autocorrelation. We follow the same strategy and test for structural breaks. The null hypothesis of no breakpoints can be rejected (p-value $<0.1 \%$ ) and the test shows a most likely location of the break in the fourth quarter of 2006. But even for the estimation with the respective dummy variable (D1) we get autocorrelation and cannot reject structural breaks (see column (II) in Table 2). Therefore we look for big outliers in the residuals by visual inspection. We can identify such outliers in the fourth quarter of 2002 and the fourth quarter of 2003. To control for these outliers we introduce a second dummy variable (D2) which takes care of this special effect from the first to the second outlier. The resulting estimation (see column (III) in Table 2) seems to be free from autocorrelation. Only one of the two liquidity measures has a significant effect on the GAP. A higher ILB share in debt leads to a lower GAP, whereas the ILB share in transactions has no significant effect (which is in contrast to the US result). The effect of the interest rate spread is significant and has the expected sign. The effect of the implied volatility of the FTSE is significant, but does not have the expected sign. ${ }^{9}$ For the United Kingdom a higher volatility of the FTSE leads to a lower GAP. This contradicts our idea that a higher uncertainty on the financial markets leads to a

\footnotetext{
${ }^{9}$ It should be noted that this effect is insignificant for the United States.
} 
higher GAP. One possible explanation for this result could be that ILB are seen as a hedge against some forms of financial uncertainty. In this case the price of ILB could increase, the respective yield could fall and the GAP could decrease. Similar to the US case, we estimate this specification with TSLS to take care of endogeneity concerns. Again, we use the one period lagged values of the liquidity measures as instruments. The estimation results do not change very much and are quite robust (see column (IV) in Table 2). We cannot reject the null hypothesis that our instruments are exogenous (C test) and that our liquidity measures are exogenous regressors (Durbin-Wu-Hausman test). Therefore, as in the US case, OLS is an appropriate estimation strategy.

[Table 2 about here.]

Let us have a closer look on the effect of the ILB share in outstanding debt on the GAP in the OLS baseline estimation (see column (III) in Table 2). A 1\%point increase in the share will lead do a decrease in the GAP of $0.25 \%$-points. The already high share of ILB in outstanding debt increases from $25 \%$ (2001) to $29 \%$ (2008), whereas during the financial crisis the share declined to $21 \%$ (2011). The marginal effect would result in a decrease of 1\%-point from 2001 to 2008 and an increase of $2 \%$-points from 2008 to 2011. During these time periods the actual GAP decreases from 1,64\% (2001) to 1,06\% (2008) and subsequently swells to $4,34 \%$ (2011). Obviously, also for the United Kingdom quite a large part of GAP's movements can be explained by the liquidity of ILB.

Similarly to the US estimation, we analyze whether the GAP series is influenced by the liquidity measures in a different way during the financial crisis (see column (V) in Table 2). The endogenously determined dummy variable interacts with the significant regressors from the OLS estimation (see column (III) in Table 2). Since the coefficient of the ILB share in debt is highly significant and its interaction term with the dummy variable is at the brink of significance $(\mathrm{p}$-value $=10.79 \%$ ), we can interpret the coefficients: A $1 \%$-point increase in the ILB share will lead do a decrease in the GAP of $0.31 \%$-points, but during the financial crisis this effect will be lowered by about $0.08 \%$-points. 


\section{Canada}

For Canada the OLS baseline estimation also shows clear signs of autocorrelation (see column (I) in Table 3). Once again, we can reject the null hypothesis of no breakpoints (p-value $<0.1 \%$ ), and the structural break is most likely located in the second quarter of 2007. If we estimate the equation with an appropriate dummy variable (D1) and test for further structural breaks we get a second breakpoint in the third quarter of 2010. Therefore we revise our dummy variable and do only control for an effect between the second quarter of 2007 and the second quarter of 2010. Even with this specification (see column (II) in Table 3) we still get clear signs of autocorrelation. Similar to the UK case, we now look for big outliers in the residuals by visual inspection. The biggest outlier can be found in the third quarter of 2008. To control for this effect we introduce an additional dummy variable (D2), which controls for an extra effect in all quarters of 2008 and is obviously successful in eliminating autocorrelation (see column (III) in Table 3). Once again, only one of our liquidity measures is significant. A higher ILB share in debt leads to a decrease in the GAP. Similar to the United Kingdom, the effect of ILB share in transactions is not significant. In the Canadian case all uncertainty measures have statistically insignificant effects. As a robustness test we do the same TSLS estimation as in the US and the UK cases. We get comparable results (see column (IV) in Table 3) with the exception of the $\mathrm{C}$ test. The p-value of the $\mathrm{C}$ test is 0.0989 and therefore we could reject the null hypothesis of both instruments being exogenous at the $10 \%$ significance level. Because this p-value is on the brink of not rejecting the null hypothesis and the estimation results are quite robust we conclude, that OLS could be an appropriate estimation strategy for Canada too. But you should keep in mind that our instruments are perhaps not appropriate in this case.

[Table 3 about here.]

Nevertheless, let us explain the estimated coefficient of the ILB share in debt in the OLS estimation. A 1\%-point increase in the share will lead to a decrease in the GAP of $1.27 \%$-points. This effect is much larger in size than the UK and US results. The ILB share in outstanding debt increases steadily from approx. $4.4 \%$ in 2003 to $6.6 \%$ in 2008 . Then, within two quarters the share slumps to only $5.5 \%$, where it remains more or less stable until 2011 (5.4\%). Considering 
the marginal effect this development would result in a decrease of the GAP of $2.8 \%$-points in the period from 2003 to 2008 and a subsequent increase of the GAP of about $1.4 \%$-points. In the period from 2003 to 2008 the actual GAP decreases from $1.97 \%$ to $0.6 \%$ and in the next quarters it increased to about $2.0 \%$. In the following years the GAP decreases again and is in 2011 lower than $1 \%$. With the exception of this last development the marginal effect of the ILB share in outstanding debt delivers an explanation for a remarkable part of the Canadian GAP's development.

Finally, as in the US and UK cases, column (V) in Table 3 shows the estimation with an interaction between the dummy variable $D 1$ and the significant regressor. Both, the coefficient of the ILB share in debt and of its interaction term, are highly significant and we can interpret them: A 1\%-point increase in the ILB share will lead do a decrease in the GAP of $1.42 \%$-points, but during the financial crisis a similar effect as in the United Kingdom is present: The decrease due to a higher ILB share is lowered by about $0.19 \%$-points.

Let us summarize the main results of the regression analysis: In all three countries the difference between observed and hypothetical yields (i.e., the GAP) is related to the liquidity of ILB. We can find statistically and economically significant effects of at least one liquidity measure on the GAP in each country. A higher liquidity of ILB will ceteris paribus lead to a lower GAP. The marginal effect of a 1\%-point increase in the share of ILB in outstanding debt on the GAP is very similar in the United States and the United Kingdom: a decrease of $0.17 \%$ points and 0.25\%-points, respectively. In Canada this effect is much larger and amounts to a decrease of $1.27 \%$-points. The share of ILB in transactions only has a significant effect on the GAP in the United States: An increase of 1\%-point in this share will result in a 1.05\%-point decrease of the GAP. Interaction terms for all significant ILB-specific measures additionally shed light on their impact during the financial crisis. The estimations indicate that the effects of liquidity on the GAP series are lower during financial turmoil. 


\section{Conclusions}

This paper contributes to recent research concerning the liquidity of inflationlinked bonds (ILB). This is crucial, since a high liquidity premium reduces Treasuries' savings. The primary idea of issuing ILB was to save money since the yields of these bonds do not contain an inflation risk premium and hence should be lower than their nominal counterparts. However, low liquidity and therefore a high liquidity premium raises ILB yields and diminishes potential savings. Recent literature focuses on the liquidity premium and some of the studies conclude that the issuance of ILB was even more expensive than issuing nominal bonds. Furthermore, these studies find that the liquidity premium is not constant over time and is rather high in the first years of issuance as well as during times of financial turmoil.

This paper summarizes recent research concerning this premium and presents an additional method to estimate the effect of liquidity on ILB yields. We calculate hypothetical ILB yields in the vein of Campbell \& Shiller (1996) for the United States, the United Kingdom as well as for Canada and subtract these synthesized yields from observed ILB yields. This difference, called the GAP series, is the basis for the regression analysis in which we show to what extent this difference is related to the liquidity of ILB. Using ILB-specific liquidity and financial markets' uncertainty measures, we find statistically and economically significant effects of the liquidity measures for all three countries: The GAP series (i.e., the difference between observed and hypothetical ILB yields) is related to the liquidity of ILB and at least one liquidity measure has a significant impact in each country. A higher liquidity of ILB will ceteris paribus lead to a lower GAP. A $1 \%$-point increase in the share of ILB in outstanding debt will have a marginal effect on the GAP series of $-0.17 \%$-points for the United States and -0.25\%-points for the United Kingdom, respectively. In Canada, the same 1\%-point increase in the share of ILB in outstanding debt has a much larger effect of $-1.27 \%$-points on the GAP series. 


\section{References}

Beber, A., Brandt, M. W. \& Kavajecz, K. A. (2009), 'Flight-to-quality or flight-to-liquidity? evidence from the euro-area bond market', Review of Financial Studies 22(3), 925-957.

Campbell, J. Y. \& Shiller, R. J. (1996), 'A scorecard for indexed government debt', NBER Macroeconomics Annual 11, 155-197.

Campbell, J. Y., Shiller, R. J. \& Viceira, L. M. (2009), 'Understanding inflation-indexed bond markets', Brookings Papers on Economic Activity 40(1), 79-138.

D'Amico, S., Kim, D. H. \& Wei, M. (2010), 'Tips from TIPS: The informational content of treasury inflation-protected security prices', Finance and Economics Discussion Series 2010-19, Board of Governors of the Federal Reserve System.

Deacon, M., Derry, A. \& Mirfendereski, D. (2004), Inflation-indexed Securities: Bonds, Swaps and Other Derivatives, Wiley.

Fama, E. F. (1975), 'Short-term interest rates as predictors of inflation', American Economic Review 65(3), 269-82.

Grishchenko, O. V. \& Huang, J.-Z. (2013), 'Inflation risk premium: evidence from the TIPS market', Journal of Fixed Income 22(4), 5-30.

Gürkaynak, R. S., Sack, B. \& Wright, J. H. (2010), 'The tips yield curve and inflation compensation', American Economic Journal: Macroeconomics 2(1), 70-92.

Lütkepohl, H. (2007), New Introduction to Multiple Time Series Analysis, Springer.

Mishkin, F. (2003), The Economics of Money, Banking, and Financial Markets, Pearson.

Pflueger, C. E. \& Viceira, L. M. (2011), 'An empirical decomposition of risk and liquidity in nominal and inflation-indexed government bonds', NBER Working Papers (16892), National Bureau of Economic Research.

Rose, A. K. (1988), 'Is the real interest rate stable?', Journal of Finance 43(5), 1095-1112.

Shen, P. (1998), 'Features and risks of treasury inflation protection securities', Economic Review 83(1), 23-38.

Shen, P. (2006), 'Liquidity risk premia and breakeven inflation rates', Economic Review 91(2), 29-54. 


\section{Appendix}

\section{Construction of hypothetical ILB yields}

The construction of hypothetical ILB yields can be summarized in detail as follows: We use the annualized 3-month nominal T-bill yields derived from Bloomberg at monthly frequency and calculate quarterly log-yields. Log-yields are common in finance since they indicate a continuous compounding which makes the returns comparable across assets. We convert the monthly log-yields into quarterly data $\left(y_{t}^{n o m}\right)$. This transformation into quarterly data has the advantage that the yields of 3-month nominal T-bills equal their returns. This is the case since the 3-month nominal T-bills can be interpreted as zero-coupon bonds and do not pay out any coupons during their term.

In a next step, we calculate the quarterly inflation rates over the previous quarter $\left(\pi_{t}^{Q}\right)$ out of monthly consumer price index data:

$$
\pi_{t}^{Q}=\ln (C P I)_{q}-\ln (C P I)_{q-1},
$$

whereas $C P I$ means the consumer price index and the subscript $q-1$ implies the index one quarter ago to calculate the quarterly inflation rates $\left(\pi_{t}^{Q}\right)$. Again, we transform this monthly data into quarterly data. The values of the quarterly data correspond to the last values of the quarter in the monthly data (i.e., the last month of the quarter). Thus, the value of March is assigned for the first quarter, the value of June for the second quarter, and so on.

The real T-bill yields $y_{t}^{\text {real }}$ can be computed as the difference between current nominal T-bill yields $y_{t}^{\text {nom }}$ and the inflation rate of the previous quarter $\pi_{t-1}^{Q}$. The inflation rate of the previous quarter is used as the current expected inflation rate. The idea is that the inflation rate follows a random walk and the best predictor of the current quarterly inflation rate is the one of the previous quarter (see, e.g., Rose (1988) or Fama (1975)):

$$
\pi_{t(e)}^{Q}=\pi_{t-1}^{Q}+\varepsilon
$$

and

$$
E\left(\pi_{t(e)}^{Q}\right)=\pi_{t-1}^{Q},
$$

where $\varepsilon$ is a stochastic error term with $E(\varepsilon)=0$.

Thus, the real T-bill yields are computed by

$$
y_{t}^{\text {real }}=y_{t}^{\text {nom }}-\pi_{t-1}^{Q}
$$

In order to compute the forecast for the real T-bill yields, we firstly put the real T-bill yields $y_{t}^{\text {real }}$ together with the inflation rate of the previous year $\pi_{t-1}^{Y}$ and the lagged nominal T-bill yields $y_{t-1}^{n o m}$ into a VAR model. ${ }^{10}$ The yearly inflation rate is used because we expect

\footnotetext{
${ }^{10}$ The inflation rate of the previous year $\pi_{t-1}^{Y}$ is used with the same considerations as the
} 
that investors may be more concerned about yearly changes in the price level. The lagged nominal T-bill yields are applied due to reasons of multicollinearity since the current nominal T-bill yields are used to calculate the real T-bill yields. If we do not lag the nominal yields, the nominal and real T-bill yields would exhibit a linear and non-stochastic relation which would make the estimation infeasible. The following equations summarize our VAR specification: ${ }^{11}$

$$
\begin{aligned}
y_{t}^{\text {real }} & =\alpha_{0}+\alpha_{1} y_{t-1}^{\text {real }}+\alpha_{2} y_{t-2}^{\text {nom }}+\alpha_{3} \pi_{t-2}^{Y}+u_{t}^{\text {real }} \\
y_{t-1}^{\text {nom }} & =\beta_{0}+\beta_{1} y_{t-1}^{\text {real }}+\beta_{2} y_{t-2}^{\text {nom }}+\beta_{3} \pi_{t-2}^{Y}+u_{t}^{\text {nom }} \\
\pi_{t-1}^{Y} & =\gamma_{0}+\gamma_{1} y_{t-1}^{\text {real }}+\gamma_{2} y_{t-2}^{\text {nom }}+\gamma_{3} \pi_{t-2}^{Y}+u_{t}^{\pi}
\end{aligned}
$$

Then, we calculate the fitted values for the real T-bill yields $\hat{y}_{t}^{\text {real }}$ of the VAR model which represent the forecast for the real T-bill yields (the so-called ex ante real T-bill yields).

$$
\hat{y}_{t}^{\text {real }}=\hat{\alpha}_{0}+\hat{\alpha}_{1} y_{t-1}^{\text {real }}+\hat{\alpha}_{2} y_{t-2}^{\text {nom }}+\hat{\alpha}_{3} \pi_{t-2}^{Y}
$$

Furthermore, we perform a forecast to receive the hypothetical yields on a 10 year ILB. A 40 step forecast can be performed by recursively computing the predictors (see, e.g., Lütkepohl (2007)):

$$
\begin{gathered}
y_{t+1 \mid t}^{\text {real }}=\alpha_{0}+\alpha_{1} y_{t}^{\text {real }}+\alpha_{2} y_{t-1}^{\text {nom }}+\alpha_{3} \pi_{t-1}^{Y} \\
y_{t+2 \mid t}^{\text {real }}=\alpha_{0}+\alpha_{1} y_{t+1 \mid t}^{\text {real }}+\alpha_{2} y_{t}^{\text {nom }}+\alpha_{3} \pi_{t}^{Y} \\
y_{t+3 \mid t}^{\text {real }}=\alpha_{0}+\alpha_{1} y_{t+2 \mid t}^{\text {real }}+\alpha_{2} y_{t+1 \mid t}^{\text {nom }}+\alpha_{3} \pi_{t+1 \mid t}^{Y} \\
\vdots \\
y_{t+40 \mid t}^{\text {real }}= \\
\end{gathered}
$$

The mean over all 40 quarter forecasts in time $t$ is expected to be the yield in time $t$ for a 10 year hypothetical ILB:

$$
\text { yield }_{t}^{10 y e a r}=\frac{1}{40} \times \sum_{h=1}^{40} y_{t+h \mid t}^{\text {real }}
$$

Calculating then the average of the forecasts for each $t$ will result in a time series of hypothetical ILB yields.

inflation rate of the previous quarter above.

${ }^{11}$ Note that similar to Campbell \& Shiller (1996), we choose a lag length of 1 because of the small number of observations included. 
Table 1: US estimation results

\begin{tabular}{|c|c|c|c|c|}
\hline Explanatory variables & (I) & (II) & (III) & (IV) \\
\hline Constant & $\begin{array}{c}3.5437^{* * * *} \\
(0.4515)\end{array}$ & $\begin{array}{c}4.2872^{* * *} \\
(0.4557)\end{array}$ & $\begin{array}{c}4.8229 * * * \\
(0.6283)\end{array}$ & $\begin{array}{c}4.3686^{* * *} \\
(0.4674)\end{array}$ \\
\hline ILB share in transactions & $\begin{array}{c}-0.7775^{* * *} \\
(0.2449)\end{array}$ & $\begin{array}{c}-1.0483^{* * *} \\
(0.2304)\end{array}$ & $\begin{array}{c}-1.6033^{* * *} \\
(0.4724)\end{array}$ & $\begin{array}{c}-1.1684^{* * *} \\
(0.3125)\end{array}$ \\
\hline ILB share in debt & $\begin{array}{c}-0.1544^{* * *} \\
(0.0521)\end{array}$ & $\begin{array}{c}-0.1653^{* * *} \\
(0.0460)\end{array}$ & $\begin{array}{l}-0.1118 \\
(0.0709)\end{array}$ & $\begin{array}{c}-0.1465^{* *} \\
(0.0644)\end{array}$ \\
\hline Implied volatility of $10 \mathrm{Y}-$ Notes & $\begin{array}{l}0.1191^{*} \\
(0.0610)\end{array}$ & $\begin{array}{c}0.0630 \\
(0.0563)\end{array}$ & $\begin{array}{c}0.0302 \\
(0.0678)\end{array}$ & $\begin{array}{c}0.0617 \\
(0.0585)\end{array}$ \\
\hline Implied volatility of S\&P500 & $\begin{array}{l}-0.0009 \\
(0.0131)\end{array}$ & $\begin{array}{l}-0.0076 \\
(0.0117)\end{array}$ & $\begin{array}{c}-0.0094 \\
(0.01318)\end{array}$ & $\begin{array}{l}-0.0088 \\
(0.0118)\end{array}$ \\
\hline Interest rate spread & $\begin{array}{c}2.6063^{* * *} \\
(0.7496)\end{array}$ & $\begin{array}{c}3.0910^{* * * *} \\
(0.6758)\end{array}$ & $\begin{array}{c}3.0831^{* * * *} \\
(0.8008)\end{array}$ & $\begin{array}{l}2.5715^{*} \\
(1.4213)\end{array}$ \\
\hline D1 & & $\begin{array}{c}0.4613^{* * * *} \\
(0.1382)\end{array}$ & $\begin{array}{c}0.5894 * * * \\
(0.1738)\end{array}$ & \\
\hline D1 $\times$ ILB share in transactions & & & & $\begin{array}{c}0.1889 \\
(0.4904)\end{array}$ \\
\hline D1 $\times$ ILB share in debt & & & & $\begin{array}{c}0.0263 \\
(0.0992)\end{array}$ \\
\hline D1 $\times$ Interest rate spread & & & & $\begin{array}{c}0.4096 \\
(1.5092)\end{array}$ \\
\hline $\begin{array}{l}\text { Observations } \\
\text { adjusted R-squared } \\
\text { LM test (p-value) } \\
\text { C test (p-value) } \\
\text { Durbin-Wu-Hausman test (p-value) }\end{array}$ & $\begin{array}{c}41 \\
0.7681 \\
0.0636\end{array}$ & $\begin{array}{c}41 \\
0.8202 \\
0.3768\end{array}$ & $\begin{array}{c}40 \\
0.7793 \\
0.4538 \\
0.8889 \\
0.1855\end{array}$ & $\begin{array}{c}41 \\
0.8190 \\
0.3830\end{array}$ \\
\hline
\end{tabular}

Notes: The dependent variable GAP is the difference between the hypothetical and the observed yields of 10 year ILB. Column (I) shows the baseline OLS estimation results. Column (II) shows the OLS estimation results with consideration of the dummy variable D1. Column (III) shows the results of a TSLS estimation. As instruments we have used the one period lagged values of the ILB share in transactions and of the ILB share in debt. Column (IV) shows the OLS estimation results including an interaction of the dummy variable D1 with the significant regressors in the OLS estimation (column (II)). The table reports the p-value of the Breusch-Godfrey serial correlation LM test for the null hypothesis of no first-order serial correlation. In the case of TSLS the table reports the p-value of the $\mathrm{C}$ test for the null hypothesis of both instruments being exogenous and the p-value of the Durbin-Wu-Hausman test for the null hypothesis of both liquidity measures being exogenous regressors. Standard errors are reported in parentheses. *, $* *$ and $* * *$ denote statistical significance at the 10-percent, 5-percent and 1-percent level. 
Table 2: UK estimation results

\begin{tabular}{|c|c|c|c|c|c|}
\hline Explanatory variables & (I) & (II) & (III) & (IV) & $(\mathrm{V})$ \\
\hline Constant & $\begin{array}{c}9.3895^{* * *} \\
(1.2583)\end{array}$ & $\begin{array}{c}9.4558^{* * *} \\
(1.1969)\end{array}$ & $\begin{array}{c}10.7301^{* * *} \\
(0.7640)\end{array}$ & $\begin{array}{c}10.0843^{* * *} \\
(1.2708)\end{array}$ & $\begin{array}{l}12.1948^{* * *} \\
(0.9441)\end{array}$ \\
\hline ILB share in transactions & $\begin{array}{c}0.1794 * * * \\
(0.0588)\end{array}$ & $\begin{array}{c}0.1061 \\
(0.0648)\end{array}$ & $\begin{array}{c}0.0797 \\
(0.0405)\end{array}$ & $\begin{array}{c}0.1312 \\
(0.1148)\end{array}$ & $\begin{array}{c}0.0371 \\
(0.0558)\end{array}$ \\
\hline ILB share in debt & $\begin{array}{c}-0.2183 * * * \\
(0.0461)\end{array}$ & $\begin{array}{c}-0.2017^{* * *} \\
(0.0445)\end{array}$ & $\begin{array}{c}-0.2540 * * * \\
(0.0286)\end{array}$ & $\begin{array}{c}-0.2320^{* * *} \\
(0.0351)\end{array}$ & $\begin{array}{c}-0.3138^{* * *} \\
(0.0393)\end{array}$ \\
\hline Implied volatility of FTSE & $\begin{array}{c}-0.3324^{* * *} \\
(0.0791)\end{array}$ & $\begin{array}{c}-0.3567^{* * *} \\
(0.0760)\end{array}$ & $\begin{array}{c}-0.3828^{* * *} \\
(0.0475)\end{array}$ & $\begin{array}{c}-0.4016^{* * *} \\
(0.0497)\end{array}$ & $\begin{array}{c}-0.3298^{* * *} \\
(0.0653)\end{array}$ \\
\hline Interest rate spread & $\begin{array}{c}1.5723 \\
(1.3390)\end{array}$ & $\begin{array}{c}1.0427 \\
(1.2951)\end{array}$ & $\begin{array}{c}2.4885^{* * *} \\
(0.8286)\end{array}$ & $\begin{array}{c}2.2593^{* *} \\
(0.8982)\end{array}$ & $\begin{array}{l}-1.4677 \\
(2.0272)\end{array}$ \\
\hline D1 & & $\begin{array}{c}0.5932^{* *} \\
(0.2646)\end{array}$ & $\begin{array}{c}0.8528^{* * *} \\
(0.1683)\end{array}$ & $\begin{array}{c}0.7474^{* *} \\
(0.2845)\end{array}$ & \\
\hline D2 & & & $\begin{array}{c}1.6600^{* * *} \\
(0.2156)\end{array}$ & $\begin{array}{c}1.5876^{* * *} \\
(0.2255)\end{array}$ & $\begin{array}{c}1.5427^{* * *} \\
(0.2373)\end{array}$ \\
\hline D1 $\times$ ILB share in debt & & & & & $\begin{array}{c}0.0829 \\
(0.0502)\end{array}$ \\
\hline D1 $\times$ Implied volatility of FTSE & & & & & $\begin{array}{l}-0.1581 \\
(0.1333)\end{array}$ \\
\hline D1 $\times$ Interest rate spread & & & & & $\begin{array}{l}5.2207^{* *} \\
(2.2647)\end{array}$ \\
\hline $\begin{array}{l}\text { Observations } \\
\text { adjusted R-squared } \\
\text { LM test (p-value) } \\
\mathrm{C} \text { test (p-value) } \\
\text { Durbin-Wu-Hausman test (p-value) }\end{array}$ & $\begin{array}{c}43 \\
0.6767 \\
0.0000\end{array}$ & $\begin{array}{c}43 \\
0.7077 \\
0.0000\end{array}$ & $\begin{array}{c}43 \\
0.8865 \\
0.6965\end{array}$ & $\begin{array}{c}42 \\
0.8825 \\
0.8860 \\
0.8997 \\
0.4200\end{array}$ & $\begin{array}{c}43 \\
0.8918 \\
0.3883\end{array}$ \\
\hline
\end{tabular}

Notes: The dependent variable GAP is the difference between the hypothetical and the observed yields of 10 year ILB. Column (I) shows the baseline OLS estimation results. Columns (II) and (III) show the OLS estimation results with the consideration of dummy variables (D1 and successively D2). Column (IV) shows the results of a TSLS estimation. As instruments we have used the one period lagged values of the ILB share in transactions and of the ILB share in debt. Column (V) shows the OLS estimation results including an interaction of the dummy variable D1 with the significant regressors in the OLS estimation (column (III)). The table reports the p-value of the Breusch-Godfrey serial correlation LM test for the null hypothesis of no first-order serial correlation. In the case of TSLS the table reports the p-value of the $\mathrm{C}$ test for the null hypothesis of both instruments being exogenous and the p-value of the Durbin-Wu-Hausman test for the null hypothesis of both liquidity measures being exogenous regressors. Standard errors are reported in parentheses. $*, * *$ and ${ }^{* * *}$ denote statistical significance at the 10-percent, 5-percent and 1-percent level. 
Table 3: Canadian estimation results

\begin{tabular}{|c|c|c|c|c|c|}
\hline Explanatory variables & (I) & (II) & (III) & (IV) & $(\mathrm{V})$ \\
\hline Constant & $\begin{array}{c}3.9830 * * \\
(1.7313)\end{array}$ & $\begin{array}{c}5.5315^{* * *} \\
(1.1852)\end{array}$ & $\begin{array}{c}7.4017^{* * *} \\
(1.1113)\end{array}$ & $\begin{array}{c}6.8327^{* * *} \\
(1.6252)\end{array}$ & $\begin{array}{c}8.2364^{* * *} \\
(1.1010)\end{array}$ \\
\hline ILB share in transactions & $\begin{array}{c}0.0210 \\
(1.0739)\end{array}$ & $\begin{array}{c}0.5676 \\
(0.7228)\end{array}$ & $\begin{array}{c}0.1849 \\
(0.6081)\end{array}$ & $\begin{array}{c}-0.0288 \\
(1.0941)\end{array}$ & $\begin{array}{c}0.1834 \\
(0.5906)\end{array}$ \\
\hline ILB share in debt & $\begin{array}{c}-0.5425^{*} \\
(0.3145)\end{array}$ & $\begin{array}{c}-0.9623^{* * *} \\
(0.2217)\end{array}$ & $\begin{array}{c}-1.2685^{* * *} \\
(0.2025)\end{array}$ & $\begin{array}{c}-1.1531^{* * *} \\
(0.3128)\end{array}$ & $\begin{array}{c}-1.4184^{* * *} \\
(0.2026)\end{array}$ \\
\hline Implied volatility of $10 \mathrm{Y}-$ Notes & $\begin{array}{c}-0.0055 \\
(0.0091)\end{array}$ & $\begin{array}{c}0.0023 \\
(0.0062)\end{array}$ & $\begin{array}{c}-0.0024 \\
(0.0053)\end{array}$ & $\begin{array}{c}-0.0011 \\
(0.0065)\end{array}$ & $\begin{array}{l}-0.0045 \\
(0.0051)\end{array}$ \\
\hline Interest rate spread & $\begin{array}{l}2.9148^{*} \\
(1.5157)\end{array}$ & $\begin{array}{c}1.6412 \\
(1.0345)\end{array}$ & $\begin{array}{c}1.1563 \\
(0.8675)\end{array}$ & $\begin{array}{c}1.1199 \\
(0.9453)\end{array}$ & $\begin{array}{c}1.0956 \\
(0.8441)\end{array}$ \\
\hline D1 (revised) & & $\begin{array}{c}1.1506^{* * *} \\
(0.1956)\end{array}$ & $\begin{array}{c}1.0568^{* * *} \\
(0.1641)\end{array}$ & $\begin{array}{c}1.0318^{* * *} \\
(0.1758)\end{array}$ & \\
\hline D2 & & & $\begin{array}{c}0.9160^{* * *} \\
(0.2551)\end{array}$ & $\begin{array}{c}0.8705^{* * *} \\
(0.2885)\end{array}$ & $\begin{array}{c}0.8860^{* * *} \\
(0.2485)\end{array}$ \\
\hline D1 $($ revised) $\times$ ILB share in debt & & & & & $\begin{array}{c}0.1932^{* * *} \\
(0.0287)\end{array}$ \\
\hline $\begin{array}{l}\text { Observations } \\
\text { adjusted R-squared } \\
\text { LM test (p-value) } \\
\text { C test (p-value) } \\
\text { Durbin-Wu-Hausman test (p-value) }\end{array}$ & $\begin{array}{c}32 \\
0.0683 \\
0.0000\end{array}$ & $\begin{array}{c}32 \\
0.5850 \\
0.0035\end{array}$ & $\begin{array}{c}32 \\
0.7152 \\
0.4510\end{array}$ & $\begin{array}{l}31 \\
0.6933 \\
0.3348 \\
0.0989 \\
0.9420\end{array}$ & $\begin{array}{c}32 \\
0.7311 \\
0.5917\end{array}$ \\
\hline
\end{tabular}

Notes: The dependent variable GAP is the difference between the hypothetical and the observed yields of 10 year ILB. Column (I) shows the baseline OLS estimation results. Columns (II) and (III) show the OLS estimation results with the consideration of dummy variables (D1 and successively D2). Column (IV) shows the results of a TSLS estimation. As instruments we have used the one period lagged values of the ILB share in transactions and of the ILB share in debt. Column (V) shows the OLS estimation results including an interaction of the dummy variable D1 with the significant regressor in the OLS estimation (column (III)). The table reports the p-value of the Breusch-Godfrey serial correlation LM test for the null hypothesis of no first-order serial correlation. In the case of TSLS the table reports the $\mathrm{p}$-value of the $\mathrm{C}$ test for the null hypothesis of both instruments being exogenous and the p-value of the Durbin-Wu-Hausman test for the null hypothesis of both liquidity measures being exogenous regressors. Standard errors are reported in parentheses. ${ }^{*},{ }^{* *}$ and $*^{* *}$ denote statistical significance at the 10-percent, 5-percent and 1-percent level. 
University of Innsbruck - Working Papers in Economics and Statistics Recent Papers can be accessed on the following webpage:

http://eeecon.uibk.ac.at/wopec/

2014-05 Julia Auckenthaler, Alexander Kupfer, Rupert Sendlhofer: The impact of liquidity on inflation-linked bonds: A hypothetical indexed bonds approach

2014-04 Alice Sanwald, Engelbert Theurl: What drives out-of pocket health expenditures of private households? - Empirical evidence from the Austrian household budget survey

2014-03 Tanja Hörtnagl, Rudolf Kerschbamer: How the value of information shapes the value of commitment or: Why the value of commitment does not vanish

2014-02 Adrian Beck, Rudolf Kerschbamer, Jianying Qiu, Matthias Sutter: Car mechanics in the lab - Investigating the behavior of real experts on experimental markets for credence goods

2014-01 Loukas Balafoutas, Adrian Beck, Rudolf Kerschbamer, Matthias Sutter: The hidden costs of tax evasion - Collaborative tax evasion in markets for expert services

2013-37 Reto Stauffer, Georg J. Mayr, Markus Dabernig, Achim Zeileis: Somewhere over the rainbow: How to make effective use of colors in meteorological visualizations

2013-36 Hannah Frick, Carolin Strobl, Achim Zeileis: Rasch mixture models for DIF detection: A comparison of old and new score specifications

2013-35 Nadja Klein, Thomas Kneib, Stephan Klasen, Stefan Lang: Bayesian structured additive distributional regression for multivariate responses

2013-34 Sylvia Kaufmann, Johann Scharler: Bank-lending standards, loan growth and the business cycle in the Euro area

2013-33 Ting Wang, Edgar C. Merkle, Achim Zeileis: Score-based tests of measurement invariance: Use in practice

2013-32 Jakob W. Messner, Georg J. Mayr, Daniel S. Wilks, Achim Zeileis: Extending extended logistic regression for ensemble post-processing: Extended vs. separate vs. ordered vs. censored

2013-31 Anita Gantner, Kristian Horn, Rudolf Kerschbamer: Fair division in unanimity bargaining with subjective claims 
2013-30 Anita Gantner, Rudolf Kerschbamer: Fairness and efficiency in a subjective claims problem

2013-29 Tanja Hörtnagl, Rudolf Kerschbamer, Rudi Stracke, Uwe Sunde: Heterogeneity in rent-seeking contests with multiple stages: Theory and experimental evidence

2013-28 Dominik Erharter: Promoting coordination in summary-statistic games

2013-27 Dominik Erharter: Screening experts' distributional preferences

2013-26 Loukas Balafoutas, Rudolf Kerschbamer, Matthias Sutter: Seconddegree moral hazard in a real-world credence goods market

2013-25 Rudolf Kerschbamer: The geometry of distributional preferences and a nonparametric identification approach

2013-24 Nadja Klein, Michel Denuit, Stefan Lang, Thomas Kneib: Nonlife ratemaking and risk management with bayesian additive models for location, scale and shape

2013-23 Nadja Klein, Thomas Kneib, Stefan Lang: Bayesian structured additive distributional regression

2013-22 David Plavcan, Georg J. Mayr, Achim Zeileis: Automatic and probabilistic foehn diagnosis with a statistical mixture model

2013-21 Jakob W. Messner, Georg J. Mayr, Achim Zeileis, Daniel S. Wilks: Extending extended logistic regression to effectively utilize the ensemble spread

2013-20 Michael Greinecker, Konrad Podczeck: Liapounoff's vector measure theorem in Banach spaces forthcoming in Economic Theory Bulletin

2013-19 Florian Lindner: Decision time and steps of reasoning in a competitive market entry game forthcoming in Economics Letters

2013-18 Michael Greinecker, Konrad Podczeck: Purification and independence

2013-17 Loukas Balafoutas, Rudolf Kerschbamer, Martin Kocher, Matthias Sutter: Revealed distributional preferences: Individuals vs. teams forthcoming in Journal of Economic Behavior and Organization

2013-16 Simone Gobien, Björn Vollan: Playing with the social network: Social cohesion in resettled and non-resettled communities in Cambodia

2013-15 Björn Vollan, Sebastian Prediger, Markus Frölich: Co-managing common pool resources: Do formal rules have to be adapted to traditional ecological norms? published in Ecological Economics 
2013-14 Björn Vollan, Yexin Zhou, Andreas Landmann, Biliang Hu, Carsten Herrmann-Pillath: Cooperation under democracy and authoritarian norms

2013-13 Florian Lindner, Matthias Sutter: Level-k reasoning and time pressure in the 11-20 money request game published in Economics Letters

2013-12 Nadja Klein, Thomas Kneib, Stefan Lang: Bayesian generalized additive models for location, scale and shape for zero-inflated and overdispersed count data

2013-11 Thomas Stöckl: Price efficiency and trading behavior in limit order markets with competing insiders forthcoming in Experimental Economics

2013-10 Sebastian Prediger, Björn Vollan, Benedikt Herrmann: Resource scarcity, spite and cooperation

2013-09 Andreas Exenberger, Simon Hartmann: How does institutional change coincide with changes in the quality of life? An exemplary case study

2013-08 E. Glenn Dutcher, Loukas Balafoutas, Florian Lindner, Dmitry Ryvkin, Matthias Sutter: Strive to be first or avoid being last: An experiment on relative performance incentives.

2013-07 Daniela Glätzle-Rützler, Matthias Sutter, Achim Zeileis: No myopic loss aversion in adolescents? An experimental note

2013-06 Conrad Kobel, Engelbert Theurl: Hospital specialisation within a DRGFramework: The Austrian case

2013-05 Martin Halla, Mario Lackner, Johann Scharler: Does the welfare state destroy the family? Evidence from OECD member countries

2013-04 Thomas Stöckl, Jürgen Huber, Michael Kirchler, Florian Lindner: Hot hand belief and gambler's fallacy in teams: Evidence from investment experiments

2013-03 Wolfgang Luhan, Johann Scharler: Monetary policy, inflation illusion and the Taylor principle: An experimental study

2013-02 Esther Blanco, Maria Claudia Lopez, James M. Walker: Tensions between the resource damage and the private benefits of appropriation in the commons

2013-01 Jakob W. Messner, Achim Zeileis, Jochen Broecker, Georg J. Mayr: Improved probabilistic wind power forecasts with an inverse power curve transformation and censored regression 


\title{
University of Innsbruck
}

\section{Working Papers in Economics and Statistics}

2014-05

Julia Auckenthaler, Alexander Kupfer, Rupert Sendlhofer

The impact of liquidity on inflation-linked bonds: A hypothetical indexed bonds approach

\begin{abstract}
The sovereign's intention to issue inflation-linked bonds (ILB) is to save money. More than 15 years' experience with this financial instrument in the United States and in several other countries has led to the conclusion that these bonds are costly and basically characterized by low liquidity issues. Recently, various papers have started to analyze the impact of liquidity on ILB yields. This paper summarizes studies concerning ILB liquidity at a glance and adds a new estimation strategy of the liquidity premium based on Campbell and Shiller's (1996) hypothetical ILB yields. We calculate the difference between observed and hypothetical ILB yields, regress this time series on a set of ILB-specific liquidity as well as general market uncertainty measures and find statistically and economically significant effects of the liquidity measures for the United States, the United Kingdom and Canada.
\end{abstract}

ISSN 1993-4378 (Print)

ISSN 1993-6885 (Online) 